\title{
The Centre for Mental Health Services Development
}

\author{
Roger C. S. Moss
}

\section{Facilitating change for the better}

The design of community-based mental health services to replace institutional patterns of service has proved a weighty responsibility for districts engaged in the task. A major challenge has confronted clinicians, planners and managers of change: to seize the not-to-be-repeated opportunity of redeeming the investment in outdated buildings; to revitalise forms of practice that have become increasingly divorced from the needs of those who use these services; and to set up valid systems of care which can stand the test of time.

The Centre for Mental Health Services Development was set up in 1991 to assist the process, and to disseminate the lessons which were being learnt. It was to give special attention to the development of mental health strategies and to their implementation, with the aim of getting new services off to a sound start. Its setting-up costs were assisted by the Department of Health and the Mental Health Foundation. It formed the first component of the Institute of Health in King's College London. Its prime function was as a consultancy, but educational and research initlatives have gradually taken root. Since 1994. under a new director, the structure of the centre has been revised and developed.

The centre was born in a period of complex and confusing change, within mental health services and far beyond. The pace of cultural change has contributed to a notable increase in stress levels; political changes have amplified the voice of citizens; health service changes have striven for value for money to such an extent that there has been a severe temptation to reduce the nation's investment in the treatment of mental illness under the cloak of change; organisational changes have followed the introduction of care management, and are likely to follow the legal changes with regard to supervision of those likely to be most disturbing to the community at large. Changes like these have created additional burdens for service providers whose agendas were already strained past capacity. In this context it would have been miraculous for any organisations purporting to facilitate change to come through unscathed by criticism or misunderstanding. The centre has weathered such storms, and has learnt from them.

The facilitators recruited by the centre all had considerable experience of change in the health and social services, and included some users and carers who had proven skills in enhancing user and carer participation. They tended to find that their own previous experience, coupled with information about well researched, successful and relevant developments, was greeted ambivalently. Health and social service systems are by their nature complex and highly varied. The British mental health scene may learn from work overseas, but has to adapt it to its own strengths and peculiarities. This is not simply a task for rigorous scientific method, although that is important and valued by the centre; it is also a challenge for that blend of judgement, intuition, leadership and courage that we call management.

\section{Tools for the task}

The centre evolved a process of faclitating the construction of mental health strategles which were realistic, agreed and affordable. The process laid particular emphasis on the qualitative and quantitative assessment of need; the first was obtained by bringing the various 'stakeholders' in local mental health services together (not least service users, their relattves and friends), and the second from the best available epidemiological and public health sources. It is a fact of life that the figures required to inform a strategy fall somewhere between these two parameters; current usage of services may give some guide to the quantity of need, but such figures rarely relate closely to the new patterns of service that such strategies envisage.

Services planned to meet needs and gathered in this way do not necessarlly correspond exactly to previous patterns of service, even when these in their time have been excellent. It is the response to needs of service users and their carers that has prompted a search for:

(a) positive outreach services for those with long-term serious mental illness 
(b) a range of rapid responses to significant mental health crises based where possible in community settings, and

(c) support for and shared care with primary health care teams.

These strategles have found new energy to address those social concerns which have not directly been provided by health services: meaningful employment and use of leisure time, money and welfare rights, housing, independent advocacy, and friendship. But so often, alongside these, service users have made heart-rending pleas for genuineness, empathy and positive regard; for information about and better coordination of services; for the chance to participate in planning, delivering and auditing the services that affect them. Basic, but so often inadequately delivered.

Evaluation of the centre's work has by no means been neglected. It has an active management board, and a series of reference groups which advise on the centre's work in specialist areas. An independent evaluation of its work in several centres was conducted in the first three years. Contracts are becoming increasingly precise and demanding in terms of the visible outcomes of the work done, and the centre is holding its own against a vigorously competitive tendering market. The centre's team has undergone adaptive change, not least in response to feedback from a number of sources, and in the interests of better meeting the demands of its customers.
The centre has been responsible for a considerable number of publications, collectively and through the pens of individual consultants. Its conferences and seminars are developing. The range of its involvements in building and implementing mental health strategles continues to grow. These include help with aspects of purchasing, advice and support in the management of change, the training of mental health teams, planning in relation to special psychiatric needs, development of user and carer groups, retraction of mental hospitals, costing services, and the development of housing schemes and day services.

\section{Comment}

Three major issues which have constantly impeded progress to better services have been the patchy quality of leadership throughout mental health services, the difficulty of securing a thorough and committed joint involvement of health and social services, and the complexity of protecting funding for mental health services. The centre has probably made some headway in advancing all three of these themes, but major progress will continue to demand the commitment and determination of politicians, professionals and public.

Roger Moss, Senior Psychiatric Adviser, Centre for Mental Health Services Development, King's College London, Campden Hill Road, Kensington, London W8 7AH 